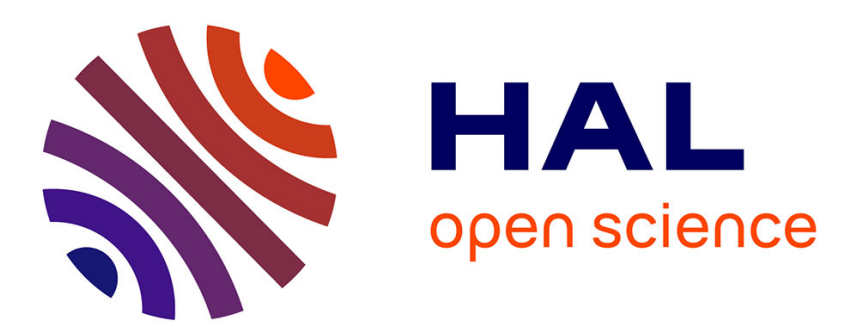

\title{
IR thermography measurement of convective coefficients in a pipe with periodic excitation
}

P. Leblay, J.-F. Henry, D. Caron, Denis Leducq, Aurore Bontemps, Laurence Fournaison

\section{- To cite this version:}

P. Leblay, J.-F. Henry, D. Caron, Denis Leducq, Aurore Bontemps, et al.. IR thermography measurement of convective coefficients in a pipe with periodic excitation. International Journal of Thermal Sciences, 2013, 74, pp.183-189. 10.1016/j.ijthermalsci.2013.06.011 . hal-02599886

\section{HAL Id: hal-02599886 \\ https://hal.inrae.fr/hal-02599886}

Submitted on 8 Oct 2020

HAL is a multi-disciplinary open access archive for the deposit and dissemination of scientific research documents, whether they are published or not. The documents may come from teaching and research institutions in France or abroad, or from public or private research centers.
L'archive ouverte pluridisciplinaire HAL, est destinée au dépôt et à la diffusion de documents scientifiques de niveau recherche, publiés ou non, émanant des établissements d'enseignement et de recherche français ou étrangers, des laboratoires publics ou privés. 


\title{
IR thermography measurement of convective coefficients in a pipe with periodic excitation
}

\author{
P. Leblay ${ }^{\text {a }}$, J.-F. Henry ${ }^{\text {b }}$, D. Caron ${ }^{\text {b }}$, D. Leducq ${ }^{\mathrm{a}, *}$, A. Bontemps ${ }^{\mathrm{c}}$, L. Fournaison ${ }^{\mathrm{a}}$ \\ ${ }^{a}$ LGP2ES Irstea-GPAN, 1, rue Pierre-Gilles de Gennes, CS 10030, 92761 Antony Cedex, France \\ ${ }^{\mathrm{b}}$ University of Reims Champagne-Ardenne, URCA/GRESPI EA4694/Thermo-mécanique, UFR Sciences, 51687 Reims Cedex 2, France

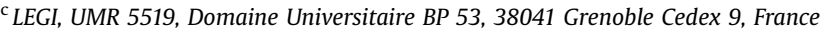

\begin{abstract}
A new methodology has been developed in order to measure heat transfer coefficients without requiring knowledge of fluid properties. This methodology is based on periodic excitation by Joule effect and infrared (IR) thermography measurement. It has been applied to measure heat transfer coefficients in the case of water flowing in a cylindrical copper tube. An analytical model has been developed to deduce heat transfer coefficients from the outside tube temperature amplitude and heat flux measurement. The Reynolds number ranges investigated are from 2000 to 14000 , with a heat flux varying from $1000 \mathrm{~W} \mathrm{~m}^{-2}$ to $5000 \mathrm{~W} \mathrm{~m}^{-2}$. The results obtained show good agreement with those obtained with a reference correlation in the literature, demonstrating the reliability of the methodology. This method can be applied to measure the heat transfer coefficients of complex shaped systems. The advantages of the method are the low heat flux required and its non-invasive nature.
\end{abstract}

\section{Introduction}

The performance of heat exchangers is highly dependent on the convective heat transfer between the walls and the fluids. The development and the design of these devices usually rely on empirical correlations, but also need precise measurements enabling validation. Infrared (IR) thermography is a reliable and non-invasive technique for such measurements.

IR measurement of convective heat transfer usually involves steady state heating and the measurement of external temperatures used as boundary conditions to solve an inverse heat conduction problem [1-5]. Transient techniques are also efficient experimental methods to measure convective heat flux under transient conditions [6-8]. The subject of the present study is the IR thermography methodology based on periodic temperature fluctuations to evaluate convective heat transfer coefficients.

Variants of this method, first developed by Hausen [9], are based on the measurement of phase shift and temperature amplitude, or the temperature amplitude ratio. These variants can be classified in

\footnotetext{
* Corresponding author.

E-mail addresses: jf.henry@univ-reims.fr (J.-F. Henry), denis.leducq@irstea.fr (D. Leducq), andre.bontemps@cea.fr (A. Bontemps).
}

four categories, depending on the configuration and the benchmark used to measure phase shift and temperature amplitude.

In the case of a fluid inside a tube, the first option consists in measuring phase shift and temperature amplitude at the outlet of the tube, using the temperature at the tube inlet as a reference. A second option is to measure the wall temperature using the fluid temperature as a reference. The third and fourth methods consist in measuring heat transfer on a surface heated by a laser device. For the third method, the phase shift and the temperature amplitude are measured over the surface considering the impact location of the laser as the reference. The fourth and last option is to measure the phase shift between the wall temperature and the heat source signal.

The first variant of the method can be illustrated by the investigation of Roetzel [10], who proposed to assess the convection heat transfer coefficient in tubes based on periodic oscillations of water flow temperature. The oscillation was generated by mixing hot and cold fluids passing through a rotary valve. The local heat transfer coefficient was deduced from a comparison of the fluid and the wall temperature oscillations. Two quantities were considered: the phase shift and the amplitude ratio between the two temperatures measured. A comparison with the values obtained using Hausen's equation [11] confirmed the reliability of the method.

The encouraging results provided by the application of the method to a tube led Roetzel et al. [12] to apply a similar method, 
developed in Roetzel et al. [13], to characterize the transfer coefficients and dispersion in plate heat exchangers. Water was used as working fluid. A steady state method, already proven, was also applied for the sole purpose of comparison for the heat transfer measurement. Temperature oscillation was measured at the inlet and the outlet of the exchanger. The phase shift between these two temperatures and the ratio of the amplitude were used. A mathematical model expresses the amplitude and the phase shift to the distribution of residence time in the exchanger and the heat transfer such that:

$\theta_{\text {th }}(P e$, NTU $)-\theta_{\text {exp }}=0$

$\varphi_{\text {th }}(P e, N T U)-\varphi_{\text {exp }}=0$

where $\varphi$ is the phase shift and $\theta$ the temperature amplitude. The results showed a good agreement between the two methods for low Reynolds numbers. However, for higher Reynolds numbers, the results obtained with the transient technique appeared to be higher than those obtained with the steady-state method. Two possible explanations for this difference were proposed. Firstly, for a high Reynolds number, the period used for the transient method was comparable with the time interval of the pneumatic valves and the flow fluctuation effect. Secondly, the steady state method did not take dispersion into account.

Recently, Freund and Kabelac [14] developed a threedimensional model which allows a rapid assessment of the distribution of heat transfer coefficients. The heat transfer coefficients are deduced from the phase shift between the heat source, usually a laser, and the temperature response of the wall. Freund et al. [15] and Freund and Kabelac [16] then applied this method in order to measure the distribution of convection coefficients on a plate cooled by jet impingement of air on one hand, and on the surface of a plate heat exchanger on the other hand. They obtained encouraging results, but specified that their model could not be transposed to shapes that are more complex than cylinders and plates.

As noted by Freund [17], heat transfer estimation requires accurate measurement of the phase shift between heat flux and temperature response. This implies using hardware that enables the time interval between heat flux and temperature measurement to be precisely determined. Without such equipment and in order to avoid errors due to synchronisation of the device, temperature oscillation measurement is not sufficient to determine the heat transfer coefficient.

The previous studies are summarized in Table 1 . The present study focuses on the IR measurement of the convective heat transfer coefficients of water in a horizontal pipe using temperature oscillations. Heating was generated here by Joule effect in order to maximize the accuracy of the measurement. The parameter considered for the evaluation of the heat transfer coefficient was the temperature amplitude measured on the outside wall by IR thermography. A heat transfer model of the system was developed in order to correlate these two quantities. This method was successfully used to evaluate convective heat transfer coefficients in a horizontal tube and was then compared to a method in which continuous heating was applied.

\section{Measurement principle}

The measuring technique was applied in order to evaluate the heat transfer coefficients between water and the inlet wall of a cylinder. The pipe was heated by Joule effect with periodic excitation. The heat flux was measured with an ammeter and a voltmeter, and the oscillation of the external surface temperature of the tube with an IR camera. Heat flux and temperature amplitude were used as entry variables in a model in order to evaluate the heat transfer coefficients.

Considering the temperature, the peak-to-peak amplitude of the oscillations varied from a few tenths of a degree to more than one degree of magnitude depending on the experimental conditions. The example presented in Fig. 1 shows that a power oscillating from $1.3 \mathrm{~W}$ to $11.0 \mathrm{~W}$ and a Reynolds number of 9200 induced a temperature amplitude of $0.35^{\circ} \mathrm{C}$. A temperature amplitude of $1.17{ }^{\circ} \mathrm{C}$ (Fig. 1) was reached with a capacity oscillating between $6.8 \mathrm{~W}$ and 18.0 W and a Reynolds number of 2500.

The copper tube was electrically heated by a sinusoidal wave DC generator whose output voltage was modulated at low frequency ( $f=0.05 \mathrm{~Hz}$ in this study).

The relationship between the periodic heating energy and the temperature oscillations for a tube, as presented in Fig. 2, comprises the heat conduction inside the tube wall and the boundary conditions. These conditions are in this case a convective heat flux imposed on the inner surface of the tube by the fluid flow and an adiabatic condition on the outer surface. External radia-

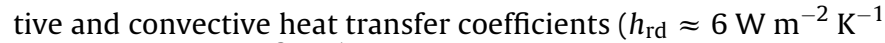
and $h_{\mathrm{cv}} \approx 4 \mathrm{~W} \mathrm{~m}^{-2} \mathrm{~K}^{-1}$ ) represent less than $1 \%$ of the internal heat transfer coefficient in the worst case. Heat losses by external convection and radiation will therefore be neglected. Considering the low capacity provided by the power supply, a second assumption is a constant fluid temperature. The third hypothesis concerns the independence of the thermodynamic properties of the material and of the convection coefficient with respect to the temperature. The fourth and last hypothesis is a $1 \mathrm{D}$ temperature variation. Angular and axial temperature variations are neglected.

The following system of equations has to be solved twice, at the excitation frequency and at twice the excitation frequency. We will not solve the continuous system of equations which does not provide additional information other than for the purposes of comparison. It includes the equation of energy conservation and the boundary conditions:

Table 1

Summary of the review of the literature.

\begin{tabular}{|c|c|c|c|c|c|c|c|}
\hline Author & Heat source & Temperature measured & Measurement method & Data & Geometry & Reynolds number & Fluid \\
\hline Roetzel [10] & Exchangers & $\begin{array}{l}\text { Fluid temperature } \\
\text { Wall temperature }\end{array}$ & Thermocouples & $\begin{array}{l}\text { Phase shift } \\
\text { Amplitude ratio }\end{array}$ & Tube & $3800<\operatorname{Re}<23200$ & Water \\
\hline Roetzel et al. [12] & Exchangers & $\begin{array}{l}\text { Inlet an outlet fluid } \\
\text { temperature }\end{array}$ & Thermocouples & $\begin{array}{l}\text { Phase shift } \\
\text { Amplitude ratio }\end{array}$ & $\begin{array}{l}\text { Plate heat } \\
\text { exchangers }\end{array}$ & $\begin{array}{l}600<\operatorname{Re}<2000400 \\
<\operatorname{Re}<1200\end{array}$ & Water \\
\hline Freund and Kabelac [14] & Laser & Wall temperature & Infrared thermography & Phase shift & Tube & $9350<\operatorname{Re}<18790$ & Water \\
\hline Freund et al. [15] & Laser & Wall temperature & Infrared thermography & Phase shift & Plate & - & Air \\
\hline Freund and Kabelac [16] & Laser & Wall temperature & Infrared thermography & Phase shift & $\begin{array}{l}\text { Plate heat } \\
\text { exchanger }\end{array}$ & $1060<\operatorname{Re}<3980$ & Water \\
\hline Present work & Joule effect & Wall temperature & Infrared thermography & $\begin{array}{l}\text { Temperature } \\
\text { amplitude }\end{array}$ & Tube & $2000<\operatorname{Re}<14,000$ & Water \\
\hline
\end{tabular}




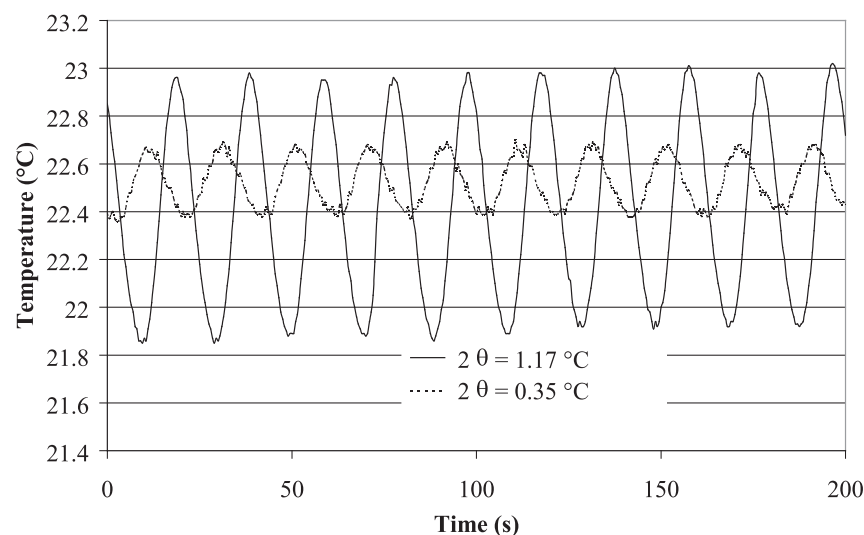

Fig. 1. Tube thermogram for a temperature peak to peak amplitude of $0.35{ }^{\circ} \mathrm{C}$ and $1.17{ }^{\circ} \mathrm{C}$.

$$
\left\{\begin{array}{l}
\frac{\partial^{2} T_{\mathrm{W}(r, t)}}{\partial r^{2}}+\frac{1}{r} \frac{\partial T_{\mathrm{w}(r, t)}}{\partial r}-\frac{1}{a} \frac{\partial T_{\mathrm{W}(r, t)}}{\partial t}=-\frac{\dot{q}_{(t)}}{k} \\
r=R_{\mathrm{i}}-\left.k \frac{\partial T_{\mathrm{w}(r, t)}}{\partial r}\right|_{r=R_{\mathrm{i}}}=h\left(T_{\mathrm{f}}-T_{\mathrm{W}\left(R_{\mathrm{i}}, t\right)}\right) \\
r=R_{\mathrm{O}}-\left.k \frac{\partial T_{\mathrm{w}(r, t)}}{\partial r}\right|_{r=R_{\mathrm{o}}}=0
\end{array}\right.
$$

where $\dot{q}$ the power density, $k$ the conductivity of the material, $h$ the heat transfer coefficient and $T_{\mathrm{w}}$ and $T_{\mathrm{f}}$ respectively the wall and the fluid temperature. The power density has three components: a continuous one, one at the excitation frequency, and one at a frequency twice the excitation frequency. The power density is given by:

$$
\dot{q}_{(t)}=\dot{q}_{c}+\dot{q}_{\omega} \exp (j \omega t)+\dot{q}_{2 \omega} \exp (j 2 \omega t)
$$

Temperature, like power, has three components. By defining:

$\theta_{(r, t)}=\left(T_{\mathrm{w}(r, t)}-T\right)$

and assuming a periodic established state, we obtain:

$\theta_{(r, t)}=\theta_{c(r)}+\theta_{\omega(r)} \exp \left(j\left(\omega t+\varphi_{\omega}\right)\right)+\theta_{2 \omega(r)} \exp \left(j\left(2 \omega t+\varphi_{2 \omega}\right)\right)$

where $\varphi$ is the phase shift between the temperature and the heat source. The resolution of the system provides the expression of $\theta_{\omega(r)}$ $\exp \left(j \varphi_{\omega}\right)$ :

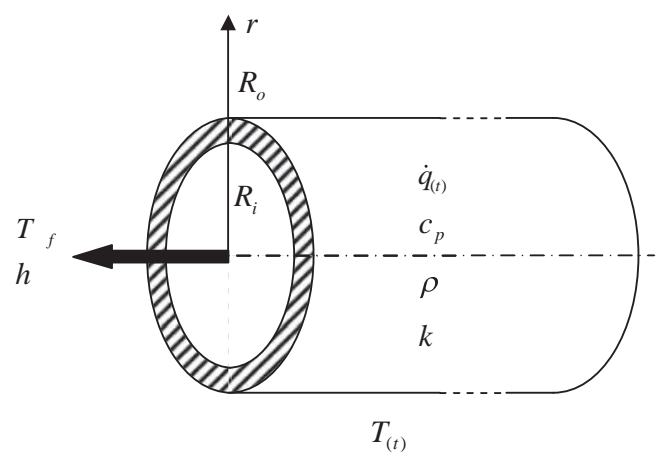

Fig. 2. Representation of the tube and related quantities.

$$
\begin{aligned}
\theta_{\omega(r)} \exp \left(j \varphi_{\omega}\right)= & \frac{\dot{q}_{\omega}}{m_{\omega}^{2} k}+\frac{h \dot{q}_{\omega}}{m_{\omega}^{3} k^{2}}\left[K_{1}\left(m_{\omega} R_{\mathrm{o}}\right) I_{0}\left(m_{\omega} r\right)\right. \\
& \left.+I_{1}\left(m_{\omega} R_{\mathrm{o}}\right) K_{0}\left(m_{\omega} r\right)\right] /\left(I_{1}\left(m_{\omega} R_{\mathrm{o}}\right)\right. \\
& {\left[-K_{1}\left(m_{\omega} R_{\mathrm{i}}\right)-\frac{h}{m_{\omega} k} K_{0}\left(m_{\omega} R_{\mathrm{i}}\right)\right] } \\
+ & \left.K_{1}\left(m_{\omega} R_{\mathrm{o}}\right)\left[I_{1}\left(m_{\omega} R_{\mathrm{i}}\right)-\frac{h}{m_{\omega} k} I_{0}\left(m_{\omega} R_{\mathrm{i}}\right)\right]\right)
\end{aligned}
$$

where:

$m_{\omega}=\sqrt{\frac{j \omega}{a}}$

The same resolution is then applied to obtain $\theta_{2} \omega(r) \exp \left(j \varphi_{2 \omega}\right)$. In these equations, $I_{0}, I_{1}$, and $K_{0}, K_{1}$ are the modified Bessel functions of the first and second kind respectively, of order zero and one.

After factorization of the first term, Equation (6) shows the group $h / m_{\omega} k$ and gives, after simplification:

$$
\theta_{\omega(r)} \exp \left(j \varphi_{\omega}\right)=\frac{\dot{q}_{\omega}}{m_{\omega}^{2} k}\left(1+\frac{\left[K_{1}\left(m_{\omega} R_{0}\right) I_{0}\left(m_{\omega} r\right)+I_{1}\left(m_{\omega} R_{0}\right) K_{0}\left(m_{\omega} r\right)\right]}{D}\right)
$$

with:

$$
\begin{aligned}
\mathrm{D}= & \left(I_{1}\left(m_{\omega} R_{\mathrm{o}}\right)\left[-\frac{m_{\omega} k}{h} K_{1}\left(m_{\omega} R_{\mathrm{i}}\right)-K_{0}\left(m_{\omega} R_{\mathrm{i}}\right)\right]\right. \\
& \left.+K_{1}\left(m_{\omega} R_{\mathrm{o}}\right)\left[\frac{m_{\omega} k}{h} I_{1}\left(m_{\omega} R_{\mathrm{i}}\right)-I_{0}\left(m_{\omega} R_{\mathrm{i}}\right)\right]\right)
\end{aligned}
$$

$m_{\omega} k / h$ can be written $b / h j \omega$, expression in which $b$ is the effusivity of the material, i.e. its ability to transfer a heat flux upon contact. The ratio $b / h$ is homogeneous with respect to $\sqrt{t}$.

The heat transfer coefficient is deduced from the temperature amplitude. So, knowing that:

$\theta_{(r)}=\left|\theta_{\omega(r)} \exp \left(j \varphi_{\omega}\right)+\theta_{2 \omega(r)} \exp \left(j \varphi_{2 \omega}\right)\right|$

evaluation of the $h$ value is finally obtained by minimizing $\varepsilon$ as follows:

$\varepsilon=\left|\theta_{\left(R_{\mathrm{o}}\right) \exp }-\theta_{\left(R_{\mathrm{o}}\right)}\right|$

where $\theta_{\left(R_{0}\right) \exp }$ is the experimental amplitude of the temperature oscillations. $\varepsilon$ is minimized by using the dichotomy method.

So, the model developed to deduce the heat transfer coefficient can be decomposed in three stages. The first stage is the drift compensation. Indeed, the wall temperature increases over time of a few tenths of degrees. To avoid errors due to the temperature drift, data were mathematically processed. An algorithm developed by Freund [17] compensates the temperature drift in order to enable calculation of the true amplitude of temperature oscillations. The second stage is the amplitude calculation. The temperature amplitude is calculated for each period and the mean value of these amplitudes $\theta_{\left(R_{0}\right) \exp }$ is calculated. The third stage is the estimation of the heat transfer coefficient. This value is obtained by comparison of the experimental value $\theta_{\left(R_{\mathrm{o}}\right) \exp }$ and values of $\theta_{\left(R_{\mathrm{o}}\right)}$ calculated from given heat transfer coefficients $h$.

Thus, knowledge of the properties of the tube material $c_{\mathrm{p}}, k, \rho$, the excitation frequency $f$, the power densities $\dot{q}_{\omega}$ and $\dot{q}_{2 \omega}$ and the amplitude of the measured temperature $\theta_{\left(R_{0}\right) \exp }$ enable us to determine the convective heat transfer coefficient $h$. 


\section{Experimental facility}

The tube in which the heat transfer coefficient measurements were carried out was connected to a hydraulic loop shown in Fig. 3. It was composed of a circulation pump and a water tank with a capacity of $100 \mathrm{l}$. The inner and outer diameters of the copper tube used were $6 \mathrm{~mm}$ and $8 \mathrm{~mm}$ respectively. The water flow rate was controlled by a valve and provided Reynolds numbers ranging from 2000 to 14000 . A thermocouple, located at the outlet of the tube, measured the water temperature during experiments in order to check that the water temperature variation remained low. The tank temperature was controlled using a thermocouple connected to the data logger. The water temperature was maintained at around $22.5^{\circ} \mathrm{C}$.

To generate the periodic heat source and to monitor and measure the temperature oscillations, the experimental facility consisted in a power supply that delivered a periodic Joule effect heating and an IR scanning device used to monitor and measure the temperature of the tube surface, as shown in Fig. 4. Considering the low resistivity of copper, the intensity reaches several hundred amperes and the voltage never exceeds $1 / 100$ th of a millivolt.

In the test section, presented in Fig. 4(a), the studied area was located $1 \mathrm{~m}$ from the flow entrance so that the requirement $L /$ $D>40$, required to avoid an entrance effect, is confirmed $(L /$ $D=200$ ). A length of $30 \mathrm{~cm}$ was heated by Joule effect at a frequency of $0.05 \mathrm{~Hz}$. This effect was located between two electrodes connected to the power supply with copper cables. A clamp ammeter and a voltmeter were connected to the data logger in order to measure the electric current in the tube and voltage between the two electrodes over time. The thermographic camera (Titanium Cedip) measured the temperature on the external surface of the tube at a frequency of $2 \mathrm{~Hz}$. This made it possible to record 400 points in $200 \mathrm{~s}$ and thus 10 periods. The external surface was painted black in order to increase and homogenize its emissivity. The area observed by the camera was located in the middle of the area heated by Joule effect.

The heat flux transferred to water along the considered area represents, in the worst case, $1.2 \mathrm{~W}$. The temperature variation between the inlet and the outlet of the area considered represents $0.03 \mathrm{~K}$, which is lower than the standard deviation, equal to $0.04 \mathrm{~K}$. The wall temperature can thus be considered uniform over the measured area.

The camera spatial resolution is calculated from the camera field and the detector size. The detector is composed of $640 \times 512 \mathrm{px}^{2}$. The image width is of $4.8 \mathrm{~cm}$, which gives a pixel size of $0.075 \mathrm{~mm}$. To obtain reliable measurements, it is necessary to take two to three

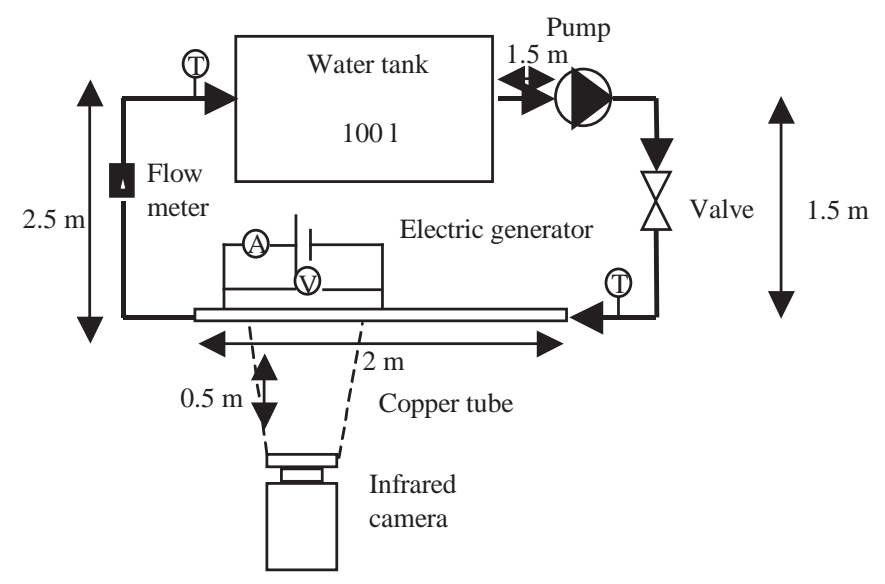

Fig. 3. Hydraulic circuit. pixels into account, which gives a spatial resolution, under operating conditions, of almost $0.2 \mathrm{~mm}$. The area represents $12 \times 2.4 \mathrm{~mm}^{2}$ and the measured temperature is the mean of the pixels of the area.

\section{Experimental results}

The experiments were conducted for a large range of water flow rates. The results obtained experimentally were compared with values obtained from Gnielinski's correlation [18]. The thermodynamic properties were considered at mean temperature, such that:

$T_{\mathrm{m}}=\frac{T_{\mathrm{in}}+T_{\text {out }}}{2}$

Gnielinski's correlation [18], adapted to transitional and turbulent flows, is given by:

$N u_{D_{\mathrm{h}}}=\frac{\Lambda / 8\left(\operatorname{Re}_{D_{\mathrm{h}}}-1000\right) \operatorname{Pr}}{1+12.7 \sqrt{\Lambda / 8}\left(\operatorname{Pr}^{2 / 3}-1\right)}\left[1+\left(D_{\mathrm{h}} / L\right)^{2 / 3}\right]\left(\operatorname{Pr} / \operatorname{Pr}_{\mathrm{w}}\right)^{0.11}$

where $L$ is the length of establishment of the flow in the tube before the measurement point, $P r_{\mathrm{w}}$ is the value of the Prandtl number at wall temperature and $\Lambda$ is the Darcy friction factor defined by:

$\Lambda=0.3164 / \operatorname{Re}_{D_{\mathrm{h}}}^{1 / 4}$

This correlation is valid for $1.5<\operatorname{Pr}<500,2300<\mathrm{Re}_{D_{\mathrm{h}}}<10^{6}$ and $0<D / L<1$.

The results obtained are presented in Fig. 5. They show good agreement between experimental and theoretical results. Results are close to those obtained with Gnielinski's correlation [18] for a Reynolds number below 8000. For the highest Reynolds number, the experimental results are lower than those predicted by the correlation.

These results demonstrate the efficiency of the method for a configuration widely studied in the literature. To confirm the relevance of the oscillating method, it was compared with a wellknown method in which continuous permanent heating was applied.

\section{Discussion}

\subsection{Comparison with a steady-state method}

The steady-state method required the same experimental setup as the oscillatory method. To avoid measurement errors associated with the calibration of several devices, the two temperatures, with and without heat flux, were measured using an IR camera. The surface temperature measurement begins without a heat source. After a few seconds, the heat source is activated. We thus have two data, the water inlet temperature, given by the wall temperature without heat flux, and the wall temperature, measured after activation of the heat source. The measurement area being located in the middle of the heated part of the tube, the water temperature at this point is given by an energy balance:

$T_{\mathrm{f}}=T_{\mathrm{f}, \text { in }}+\frac{\dot{q} \pi\left(R_{o}^{2}-R_{i}^{2}\right) L}{2 \dot{m}_{\mathrm{f}} c_{\mathrm{p}, \mathrm{f}}}$

The temperature difference between the fluid temperature and the wall temperature, together with the known heat flux, made it possible to evaluate the heat transfer coefficient. Indeed, the heat transfer coefficient is given by Ref. [19]: 


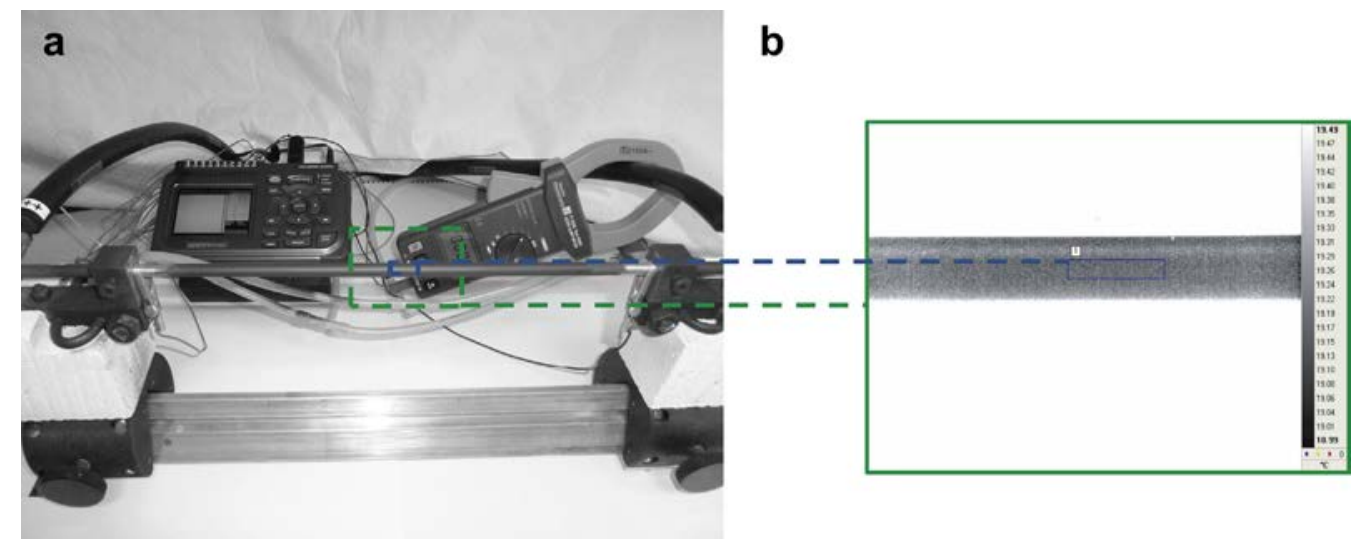

Fig. 4. Test section (a) and area considered (b).

$$
h=\frac{\dot{q}\left(R_{\mathrm{o}}^{2}-R_{\mathrm{i}}^{2}\right)}{\left.2 R_{\mathrm{i}}\left(T_{\mathrm{W}}-T_{\mathrm{f}}-\frac{\dot{q}\left(R_{\mathrm{o}}^{2}-R_{i}^{2}\right)}{4 k}\right) \frac{\left(R_{\mathrm{o}} / R_{\mathrm{i}}\right)^{2}\left(1-\ln \left(\left(R_{\mathrm{o}} / R_{\mathrm{i}}\right)^{2}\right)\right)-1}{1-\left(R_{\mathrm{o}} / R_{\mathrm{i}}\right)^{2}}\right)}
$$

In the case of an oscillatory heat flux, the capacity oscillated between $5 \mathrm{~W}$ and $29 \mathrm{~W}$ whereas the heat flux was $28 \mathrm{~W}$ for the steady-state method. Measurements were performed for various flow rates.

The two series of results reveal good agreement, as shown in Fig. 6. However, the periodic method is more stable. Moreover, with the periodic method, evaluation of heat transfer coefficients is based on the average of results obtained over several periods. Problems due to measurement noise can thus be avoided.

The periodic method only requires knowledge of material properties, heat flux and temperature evolution, which is an advantage for industrial applications. The steady state method, on the other hand, requires knowledge of the flow rate, fluid temperature and properties.

Thus, the oscillatory method provides many advantages in terms of: (i) the data needed, (ii) the material required; and (iii) enables the mean values of the heat transfer coefficients to be measured even when phenomena is disturbed by measurement noise. It also appears to be more reliable in terms of accuracy.

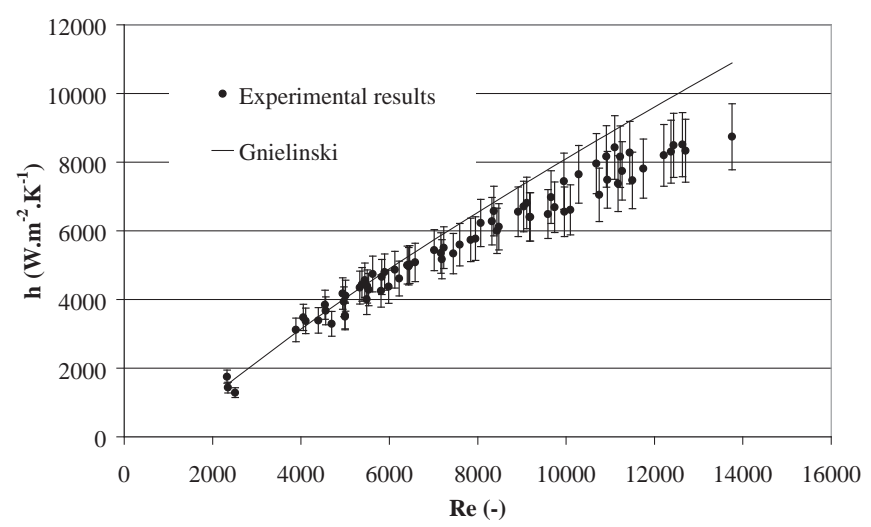

Fig. 5. Comparison of heat transfer coefficients obtained experimentally and from correlations as a function of the Reynolds number.

\subsection{Accuracy of both methods}

Considering the steady state method, the reduced sensitivity is given by:

$S=h\left(\frac{\partial \theta_{(r)}}{\partial h}\right)_{r=R_{0}}=-\frac{\bar{q}}{h} \frac{V}{S}$

Considering the periodic method, the reduced sensitivity $S$ of the measurement for the determination of the heat transfer coefficient $h$ is given by:

$S=h\left(\frac{\partial\left(\theta_{\omega}(r)+\theta_{2 \omega}(r)\right)}{\partial h}\right)_{r=R_{0}}$

The values of the reduced sensitivity for both methods, as a function of the heat transfer coefficients, are presented in Fig. 7. For the periodic method, $S$ was calculated for a frequency ranging from $0.02 \mathrm{~Hz}$ to $0.2 \mathrm{~Hz}$. For the permanent method, $S$ was calculated for a heat flux of $15 \mathrm{~W}$, corresponding to the mean value applied in the case of the periodic method.

For low heat transfer coefficient values, the sensitivity decreases with increasing excitation frequency, reflecting the influence of the time constant of the wall $\tau$ which is inversely proportional to the heat transfer coefficient:

$\tau=\frac{\rho c_{\mathrm{p}}}{h} \frac{V}{S}$

which in our case gives rise to: for $h=2000 \mathrm{~W} \mathrm{~m}^{-2} \mathrm{~K}^{-1}, \tau=1.95 \mathrm{~s}$, and for $h=10000 \mathrm{~W} \mathrm{~m}{ }^{-2} \mathrm{~K}^{-1}, \tau=0.39 \mathrm{~s}$.

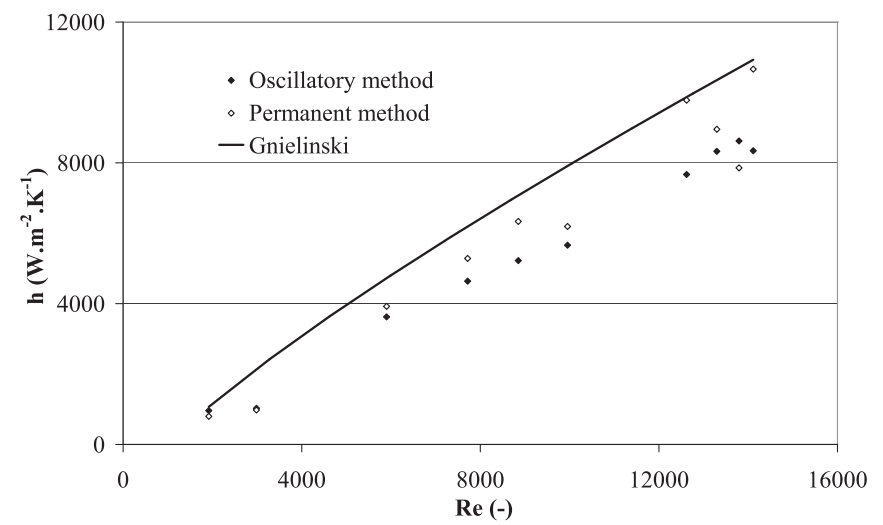

Fig. 6. Comparison of heat transfer coefficients obtained with the oscillatory method and with the permanent method as a function of the Reynolds number. 


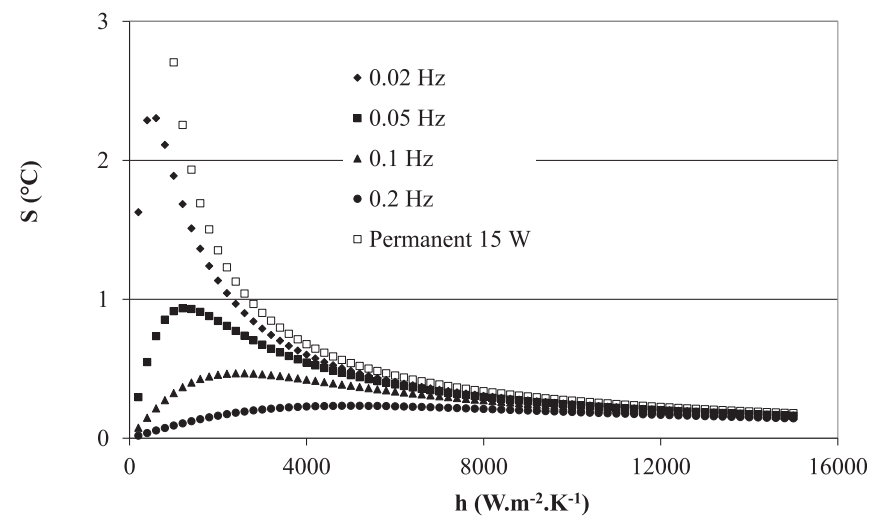

Fig. 7. Comparison of sensitivity of the oscillatory method and the permanent method as a function of the heat transfer coefficient.

Table 2

Uncertainty propagation on the well known parameters.

\begin{tabular}{lll}
\hline Variable \pm Uncertainty & Partial derivative & $\begin{array}{l}\text { \% of evaluated } \\
\text { uncertainty }\end{array}$ \\
\hline$k=400 \pm 10\left[\mathrm{~W} \mathrm{~m}^{-1} \mathrm{~K}^{-1}\right]$ & $\partial h / \partial k=-0.23$ & $0.00 \%$ \\
$c_{p}=385 \pm 10\left[\mathrm{~J} \mathrm{~kg}^{-1} \mathrm{~K}^{-1}\right]$ & $\partial h / \partial c_{p}=-0.64$ & $0.00 \%$ \\
$\rho=8700 \pm 100\left[\mathrm{~m}^{3} \mathrm{~kg}^{-1}\right]$ & $\partial h / \partial \rho=-0.03$ & $0.00 \%$ \\
$L=0.292 \pm 0.0005[\mathrm{~m}]$ & $\partial h / \partial L=-29710$ & $0.03 \%$ \\
$R_{i}=0.003 \pm 0.0002[\mathrm{~m}]$ & $\partial h / \partial R_{i}=-2678000$ & $33.22 \%$ \\
$R_{o}=0.004 \pm 0.0002[\mathrm{~m}]$ & $\partial h / \partial R_{o}=-201500$ & $0.19 \%$ \\
$U_{\min }=0.037 \pm 0.005[\mathrm{~V}]$ & $\partial h / \partial U_{\min }=-59234$ & $10.16 \%$ \\
$U_{\max }=0.090 \pm 0.005[\mathrm{~V}]$ & $\partial h / \partial U_{\max }=121399$ & $42.67 \%$ \\
$I_{\min }=139 \pm 5[\mathrm{~A}]$ & $\partial h / \partial I_{\min }=-16$ & $0.73 \%$ \\
$I_{\max }=334.5 \pm 5[\mathrm{~A}]$ & $\partial h / \partial I_{\max }=33$ & $3.06 \%$ \\
$f=0.05 \pm 0.001[\mathrm{~Hz}]$ & $\partial h / \partial f=-5050$ & $0.00 \%$ \\
$\theta=0.59 \pm 0.02[\mathrm{~K}]$ & $\partial h / \partial \theta=-14650$ & $9.94 \%$ \\
$h=8344.7 \pm 929,2\left[\mathrm{~W} \mathrm{~m}{ }^{-2} \mathrm{~K}^{-1}\right]$ & & $100 \%$ \\
\hline
\end{tabular}

If the excitation frequency is too high, the amplitude of the oscillations decreases with the accuracy.

With an excitation frequency of $0.05 \mathrm{~Hz}$, for $h=2000$ $\mathrm{W} \mathrm{m} \mathrm{m}^{-2} \mathrm{~K}^{-1}$, and with a measuring accuracy of $0.02{ }^{\circ} \mathrm{C}, h$ is obtained with an uncertainty on the model of $24 \mathrm{~W} \mathrm{~m} \mathrm{~m}^{-2} \mathrm{~K}^{-1}$. For $h=10000 \mathrm{~W} \mathrm{~m}^{-2} \mathrm{~K}^{-1}$, the accuracy reaches $416 \mathrm{~W} \mathrm{~m}^{-2} \mathrm{~K}^{-1}$.

\subsection{Uncertainty propagation}

To complete the previous study, uncertainty propagation was carried out in order to investigate the influence of all the parameters required to evaluate the heat transfer coefficient. A summary of the influence of each parameter on the uncertainty evaluated for the heat transfer coefficient is presented in Table 2. It can be seen that the measurement of temperature amplitude and heat flux exerts a major influence on the heat transfer coefficient evaluation. Geometric parameters also exert a major influence on the final value.

The thermophysical properties of the tube material exert little influence, and this is an interesting observation. This means that it is not necessary to have accurate knowledge of the properties of the material. Moreover, this confirms the weak influence of the variation in these properties according to the temperature on the resolution of the model.

\section{Conclusion}

A method has been developed in order to measure the convective heat transfer coefficient in a tube. This method is based on a modulated heat flux generated by Joule effect. In this manner, measurement of the amplitude of the temperature of the external wall of the tube with an IR thermographic camera enables internal heat transfer coefficients to be determined using a simple analytical model.

This method has the advantage of being non-invasive. It enables heat transfer to be evaluated without requiring knowledge of the flow rate, temperature or properties of the fluid. Moreover, it does not require a high heat flux, thus avoiding major effects on the fluid properties.

Thanks to its simplicity, the model can also be applied to more complex shaped tubes. Its flexibility makes it a perfect tool for controlling series of elements with similar shapes.

Future work will focus on the study of heat transfer coefficients in a multiport flat tube. Moreover, a facility allowing the measurement of the phase at the origin will allow us to determine the heat transfer coefficient with the phase shift.

\section{Acknowledgements}

This work has been supported by the Cetim Foundation as part of the research project "Two Phase Flow Distribution in a Compact Heat Exchanger".

\section{References}

[1] T.M. Adams, S.I. Abdel-Khalik, S.M. Jeter, Z.H. Qureshi, An experimental investigation of single-phase forced convection in microchannels, International Journal of Heat and Mass Transfer 41 (6-7) (1998) 851-857.

[2] H. Boye, Y. Staate, J. Schmidt, Experimental investigation and modelling of heat transfer during convective boiling in a minichannel, International Journal of Heat and Mass Transfer 50 (1-2) (2007) 208-215.

[3] J. Pettersen, Flow vaporization of $\mathrm{CO}_{2}$ in microchannel tubes, Experimental Thermal and Fluid Science 28 (2-3) (2004) 111-121.

[4] S.R. Sargent, C.R. Hedlund, P.M. Ligrani, An infrared thermography imaging system for convective heat transfer measurements in complex flows, Measurement Science and Technology 9 (12) (1998) 1974-1981.

[5] G.I. Mahmood, M.L. Hill, D.L. Nelson, P.M. Ligrani, H.K. Moon, B. Glezer, Loca heat transfer and flow structure on and above a dimpled surface in a channel, Journal of Turbomachinery 123 (1) (2001) 115-123.

[6] R.E. Critoph, M.K. Holland, M. Fisher, Comparison of steady state and transient methods for measurement of local heat transfer in plate fin-tube heat exchangers using liquid crystal thermography with radiant heating, International Journal of Heat and Mass Transfer 42 (1) (1999) 1-12.

[7] M. Rebay, A. Arfaoui, G. Mebarki, R. Ben Maad, J. Padet, Improvement of the pulsed photothermal technique for the measurement of the convective heat transfer coefficient, Journal of Thermal Science 19 (4) (2010) 357-363.

[8] Z. Wang, P.T. Ireland, S.T. Kohler, J.W. Chew, Heat transfer measurements to a gas turbine cooling passage with inclined ribs, Journal of Turbomachinery 120 (1) (1998) 63-69.

[9] H. Hausen, Wärmeübertragung im Gegenstrom, Gleichstrom und Kreuzstrom, second ed., Springer Verlag, Berlin, 1976.

[10] W. Roetzel, Measurement of heat transfer coefficients in tubes by temperature oscillation analysis, Chemical Engineering and Technology 12 (6)(1989)379-387.

[11] H. Hausen, Waerme-stoffuebertrag, 1974, p. 3.

[12] W. Roetzel, S.K. Das, X. Luo, Measurement of the heat transfer coefficient in plate heat exchangers using a temperature oscillation technique, International Journal of Heat and Mass Transfer 37 (Suppl. 1) (1994) 325-331.

[13] W. Roetzel, X. Luo, Y. Xuan, Measurement of heat transfer coefficient and axial dispersion coefficient using temperature oscillations, Experimental Thermal and Fluid Science 7 (4) (1993) 345-353.

[14] S. Freund, S. Kabelac, Measurement of local convective heat transfer coefficients with temperature oscillation IR thermography and radiant heating, in: Proceedings of the ASME Summer Heat Transfer Conference, 2005. San Francisco, CA.

[15] S. Freund, A.G. Pautsch, T.A. Shedd, S. Kabelac, Local heat transfer coefficients in spray cooling systems measured with temperature oscillation IR thermography, International Journal of Heat and Mass Transfer 50 (9-10) (2007) 1953-1962.

[16] S. Freund, S. Kabelac, Investigation of local heat transfer coefficients in plate heat exchangers with temperature oscillation IR thermography and CFD, International Journal of Heat and Mass Transfer 53 (19-20) (2010) 3764-3781.

[17] S. Freund, Local Heat Transfer Coefficients Measured with Temperature Oscillation IR Thermography, in "Thermodynamics", Helmut-Shmidt-University, Hamburg, 2008, p. 142 . 
[18] V. Gnielinski, New equations for heat and mass-transfer in turbulent pipe and channel flow, International Chemical Engineering 16 (2) (1976) 359-368.

[19] M. Ducoulombier, Ebullition convective du dioxyde de carbone - Etude expérimentale en micro-canal, Insa, Lyon, 2010.

\section{Glossary}

$a$ : thermal diffusivity $a=k /\left(\rho c_{p}\right)\left(\mathrm{m}^{2} \mathrm{~s}^{-1}\right)$

$c_{p}$ : specific heat capacity $\left(\mathrm{J} \mathrm{kg}^{-1} \mathrm{~K}^{-1}\right)$

$D$ : diameter $(\mathrm{m})$

$D_{h}$ : hydraulic diameter $(\mathrm{m})$

$f$ : frequency $\left(\mathrm{s}^{-1}\right)$

$h$ : heat transfer coefficient $\left(\mathrm{W} \mathrm{m}^{-2} \mathrm{~K}^{-1}\right)$

$j$ : imaginary number such as $j^{2}=-1(-)$

I: intensity (A)

$k$ : thermal conductivity $\left(\mathrm{W} \mathrm{m}^{-1} \mathrm{~K}^{-1}\right)$

$L$ : length $(\mathrm{m})$

$\dot{m}$ : mass flow rate $\left(\mathrm{kg} \mathrm{s}^{-1}\right)$

NTU: number of heat transfer units NTU $=h S / \dot{m} c_{\mathrm{p}}(-)$

$N u_{D_{h}}$ : Nusselt number $N u_{D_{\mathrm{h}}}=h D_{\mathrm{h}} / k(-)$

$P$ : heat flow rate $(\mathrm{W})$

$P e$ : Peclet number $P e=v \quad D_{\mathrm{h}} / a=\operatorname{RePr}(-)$

Pr: Prandtl number $P r=\mu c_{\mathrm{p}} / k(-)$

$\dot{q}$ : heat flow rate by unit of volume $\left(\mathrm{W} \mathrm{m}^{-3}\right)$

$R$ : radius $(\mathrm{m})$

$R e_{D_{h}}$ : Reynolds number $R e_{D_{\mathrm{h}}}=\rho \nu D_{\mathrm{h}} / \mu(-)$ $r$ : radial coordinate $(\mathrm{m})$

s: surface $\left(\mathrm{m}^{2}\right)$

$T$ : temperature $\left({ }^{\circ} \mathrm{C}\right)$

$t$ : time $(\mathrm{s})$

$U$ : voltage $(\mathrm{V})$

$V$ : volume $\left(\mathrm{m}^{3}\right)$

$v$ : mean velocity $\left(\mathrm{m} \mathrm{s}^{-1}\right)$

$\varepsilon$ : minimization criterion $(-)$

$\theta$ : reduced temperature $\left({ }^{\circ} \mathrm{C}\right)$

A: Darcy coefficient $(-)$

$\mu$ : dynamic viscosity (Pa s)

$\rho$ : density $\left(\mathrm{kg} \mathrm{m}^{-3}\right)$

$\varphi$ : phase delay (rad)

$\omega$ : angular pulsation $\omega=2 \pi f\left(\operatorname{rad~s}^{-1}\right)$

Subscripts

a: alternating

c: continuous part

exp: experimental

$f$ : fluid

$i$ : inside

in: inlet

$m$ : mean

$o$ : outside

out: outlet

$w$ : wall

$\omega$ : excitation angular frequency

$2 \omega$ : twice the excitation angular frequency 